\title{
THE IMPACT OF MOBILE TABLET USE ON PROCESSES
}

\author{
Nitza Davidovitch, Roman Yavich \\ Ariel University, Israel \\ E-mail: d.nitza@ariel.ac.il, romany@ariel.ac.il
}

\begin{abstract}
The purpose of the current research was to explore the impact of tablet use for various subjects in Israeli schools on students' perception of learning processes in the cognitive and affective dimensions. For this purpose, 122 ninth and tenth grade students from the Boyar School in Jerusalem completed an online questionnaire. The main hypotheses were that a difference would be found between STEM (science, technology, engineering, and mathematics) and non-STEM subjects in the weight attributed to the cognitive dimension of tablet use, as well as in the weight attributed to the affective dimension of tablet use. These hypotheses were not confirmed. In contrast, the hypothesis concerning gender differences in the weight attributed to cognitive and affective dimensions was partially confirmed. Males attributed more weight than female adolescents to both the cognitive and affective dimensions of tablet use. A possible explanation of the findings is the male inclination towards STEM subjects that include more cognitive use of learning. In future studies, it is advisable to utilize a larger sample and to thoroughly explore gender differences regarding this topic.
\end{abstract}

Keywords: STEM, tablet, learning processes, educational pedagogy.

\section{Introduction}

The technological changes witnessed in recent years are generating endless new opportunities for learning, as well as additional pedagogical challenges. Many study programs, from kindergarten to university, have embraced the advanced technological instruments as new study tools facilitating new and varied ways of achieving traditional study goals. Use of mobile technologies, such as tablets, laptops, digital books, smartphones, and more, are making it possible to consume, process, and store information everywhere, anytime, by anyone. Everyday use of these technologies is becoming gradually more available and popular for diverse needs, such as study, work, as well as forming and maintaining social relationships (Sofer, Kahn, \& Livne, 2014). The current research will deal with the use of tablets for different subjects in Israeli schools and its impact on students' perception of learning processes on the cognitive and affective dimension. Use of tablets in Israeli schools is still in its experimental stages, as part of the change that the school system is undergoing with regard to increasing access to different forms of learning, and the implications of tablet use for learning are still under investigation. The researchers would like to examine this practice, particularly regarding the differences between STEM (science, technology, engineering, and mathematics) and non-STEM subjects.

\section{Usages of the Tablet}

There is still no formal and set definition of the tablet, in light of the wide array and technological upgrades evident in constantly emerging new models. The basic principles of the mobile tablet can be found in a large variety of devices, with different sizes and operation 
OF EDUCATION

IN THE $21^{\text {st }}$ CENTURY Vol. 76, No. 1,2018

30

systems, combined with a small laptop or smartphone, which is in fact a relatively small tablet with a mobile network. The tablet is characterized by a simple intuitive user interface, and it involves processing and creating data by means of a range of media and means, with application bundles for varied usages and characterized by small dimensions, low weight, and mobility (Rotem \& Avni, 2013). In order to grasp the benefits of using tablets for pedagogic purposes at present, it is important to understand how this technology developed. The computer was created in the late 1940s to process data and information and in the late 1980s it became a popular instrument in the form of the personal computer, with creative tools for writing, processing, storing data, and more. Online communication and the internet (in the early 1990s) made it possible to consume information from an endless ocean, and this formed a connection between the wide public and computers. Thus, access was provided to information consumption, which appears to be the main public use. As a result, devices that primarily serve for information consumption were developed, and beginning from the mid-1990s hand-held computers and mobile computers emerged, relatively simple devices compared to the strength and memory required by desktop computers at the time in order to consume and update information (Rotem \& Avni, 2013).

Currently, in the second decade of the twenty first century, there is wide public access to mobile tablets originating from smartphones used to consume online information, with a variety of options for presenting, editing, and producing information through easy and user-friendly applications. The new tablets (from 2012 on) contain more tools for creating information, for instance Office Online, apps for creating and sharing such as Google Docs, side by side with numerous specially designated apps for utilizing, creating, processing, and managing information. File management is carried out primarily in a designated "cloud" on the web (Rotem \& Avni, 2013). These technologies render classroom-learning tools more efficient and make the presentation and conveying of information more flexible than via traditional methods. Many schools in Israel and elsewhere are utilizing these benefits and are beginning to use the tablet as a regular learning tool in the classroom. This process is still in its initial stages and is raising many questions regarding the contribution of mobile devices to teaching and learning and their influence on perceptions of learning, motivation, and social aspects (Sofer, Kahn, \& Livne, 2014).

\section{The Unique Role of the New Tablet-Utilizing Educational Pedagogy}

Rotem and Avni (2013) claim that tablets are generating a real revolution in teaching and learning as well as implementing an innovative educational pedagogy based on digital learning. These researchers present a model that portrays the benefits of tablets for education and how tablets enable application of pedagogic principles. They contend that the educational discourse around the world understands that education can no longer be managed without integrating the most advanced technology utilized in students' life, such as smartphones, laptops, and tablets. Within such learning, the school system provides a relevant response to the world of young students, in a language and terms compatible with their everyday world view and conduct. Tablets enable, in theory and in practice, implementation of the slogan "connecting to the student's world", which realizes the ideal pedagogy that many educators have been craving for centuries (Rotem \& Avni, 2013).

Using tablets for teaching and learning generates a pedagogically unique learning experience based on the principles of enhancing the personal motivation of each student, selfchoice, and independent and shared initiatives for implementing one's studies. In the experience of learning with tablets, learning is removed from the classroom and from the teacher's structured lesson to a space of thinking and practical autonomy. This leads to experiences that involve doing, the joy of creation and of revelation, independent gathering of information relevant for 
the student and for his and her inner world outside the class limits, and combining productive means such as still photography, video, editing, voice and text, that until recently could not even be imagined. At the same time, information is located online and utilized for the student's needs when preparing for exams, learning products are thoroughly inspected, and more, all through a single device that is held and operated by the student in person at all times (Rotem \& Avni, 2013).

According to Rotem and Avni (2013) tablets make it possible to realize many pedagogic principles such as: Student-centered learning-The personal tablet enables autonomous, personal, and joint learning, while adapting the learning to the student's uniqueness, needs, choices, and preferred manners of expression and displaying personal initiative and creativity. Creating and spreading information - Students record personal information and process raw information received from various digital materials on the web by means of diverse media according to their personal creativity and initiative. Motivation and involvement - Personal motivation and active involvement in realizing the student's overall capabilities, in order to develop self-efficacy and nurture self-value. Diverse learning - An endless variety of applications designated for specific activities, which are updated and expanded daily, and of topics, materials, and concrete information aimed at diversifying and enriching studies (Donald, 2000, Rossing, Miller, Cecil, \& Stamper, 2012, Sofer, Kahn, \& Livne, 2014).

\section{The Main Aspects of Teaching}

According to Donald (2000), optimal teaching is achieved first and foremost when students learn efficiently. Namely, good teaching is defined by the outcome - good learning by students. Hativa (2014) contends that in order to reach optimal teaching it is necessary to achieve multidimensional goals in addition to learning certain material. These goals are situated along two major dimensions: the cognitive dimension and the affective dimension. The cognitive dimension includes developing problem solving skills and independent learner skills, efficient management of time, and the ability to cope with difficulties and with the tendency to procrastinate, as well as promoting critical and creative thinking. The affective dimension consists of developing and changing attitudes and promoting interest in and motivation for learning. In conclusion, efficient teaching is that which, in addition to developing understanding of the study material, will facilitate development and a variety of other skills and capabilities.

In her model of good teaching, Hativa (2014) provides details of the cognitive and affective dimensions as follows: The cognitive dimension consists of conveying the material to the students and organization of the course/lesson - Students who are present in class are aware of the stages through which the teacher proceeds, what has been studied so far and what will be studied next, with the lesson well utilized for learning. Lesson clarity - The teacher presents clear well-structured explanations that let the students understand the course of the lesson and the study material. This in such a way that they are able to apply their understanding and perform assignments based on the study material. Enhancing concentration and attention as well as intellectual challenge - The teacher manages to maintain the students' concentration and their involvement in the entire lesson. At the same time, the affective dimension consists of the generation of a pleasant class atmosphere and reinforces openness and the desire to learn. This dimension is comprised of maintaining positive and beneficial interactions with the students - encouraging them to pose questions and providing helpful answers to their questions. Displaying respect, empathy, and caring - Further, providing students with assistance and, in general, displaying a warm and loving approach towards the students.

Hativa (2014) mentions Biglan's (1973) model, investigating which topics of instruction were preferred by engineering students, who represented STEM subjects, and which were preferred by humanities students, who represented non-STEM subjects. When ranking the

\begin{tabular}{|l} 
PROBLEMS \\
OF EDUCATION \\
IN THE 21 $1^{\text {st }}$ CENTURY \\
Vol. 76, No. 1, 2018 \\
\hline 31
\end{tabular} 


\section{PROBLEMS \\ OF EDUCATION \\ IN THE $21^{\text {st }}$ CENTURY Vol. 76, No. 1, 2018 \\ 32}

aspects of lesson clarity and organization as well as the lecturer's positive responses to questions (the cognitive dimension), STEM students attributed greater weight to these than did non-STEM students. For students of STEM subjects, it was much more important than for students of nonSTEM subjects that lessons be organized, clear, and include good teacher-student interactions. In contrast, students of non-STEM subjects found it particularly important, more than students of STEM subjects, that lessons be interesting and fascinating and that the teacher make an effort to maintain students' concentration and attention. In addition, the clarity of teaching is the most important quality for students of STEM subjects, more than any other quality of good teachers. In this way, students of STEM subjects appear to rank cognitive items higher.

\section{Cognitive and Affective Dimensions of Tablet Use}

Various studies on tablet use in schools in Israel and elsewhere show that the cognitive dimensions mentioned by Hativa (2014) are manifested in learning: In aspects of lesson organization - when using tablets for learning, in order to create an optimal and clear learning environment, the teacher must know how to adapt the lesson structure and the material taught to the technology used - learning app, presentation, films, etc. (Harris, Mishra, \& Kochler, 2009). Organizing learning in this new way can help the student become better oriented to the lesson's contents. In addition, the teacher must be familiar with operation of the tablet in order to guide students on where to search for material when necessary (Mang \& Wardley, 2012). Regarding the aspect of lesson clarity - the tablet is a tool for gathering information and for constructing models by the students, by expanding the options for activity and discourse in class in different directions. Students can implement their understanding of the lesson and extend their knowledge of the study material so that the teacher will be able to know what the student managed to grasp (Sharples, Taylor, \& Vavoula, 2010).

In the aspects of intellectual challenge and enhancing concentration and attention, mentioned by Hativa, the student is intellectually challenged while learning by means of the apps available on the tablet - such as games, worksheets, etc. Learning also takes place in "real time", in class. For instance, the student may see the country about which he is learning on the tablet, becoming familiar with its location and population. In this way learning is not only theoretical, rather also visual and more interesting (Sharples et al., 2010). In a research on students' perception of learning by means of tablets, students claimed that this type of learning helped them be more concentrated in class than in lessons with no tablet. Learning with a tablet also helps them learn the content of the lesson, acquire command of the study material, wish to be more present in class and more concentrated. Moreover, it was claimed that the tablet helps them improve their abilities when performing in class beyond that possible in the traditional method of learning (Rossing, Miller, Cecil, \& Stamper, 2012). In a research conducted by Borse and Sloan (2005), fourth to eighth graders who studied in classes that used tablets reported more active participation in learning. Furthermore, improvements were evident in their writing performance, as well as higher rates of homework done and very little absence from school (Couse \& Chen, 2010).

In addition to the cognitive dimension, the tablet has many benefits for learning on the affective dimension as well. In the aspect of interaction between students: Learning with a tablet facilitates easier interaction and communication between the student and the teacher and among the students themselves. Moreover, it lets the students carry out joint actions, create files and share them, and participate in different learning communities (Melhuiah \& Faloon, 2010). Furthermore, the size of the tablet and its features make it into an ideal tool for discussions and interactions in small groups. In this way, students can synchronize information and files online. There are applications that are intended and adapted for such joint activity between students (Rossing, Miller, Cecil \& Stamper, 2012). There is also the aspect of student-teacher interaction, 
where this learning is based on a change in the teacher's role to that of one who guides and leads the student to autonomous learning while directing him or her to central contents, accessibility and use of digital teaching-learning material and units, side by side with online information sources. This is in order to structure inquiry-based knowledge while sharing, expanding, and intensifying learning through accessible and active academic-social communication (Rotem \& Avni, 2013).

The affective dimension includes motivation as well: Various studies have found that the tablet increases motivation to study and students' desire to attend class. The tablet also causes students to be more attentive and involved in class (Rossing et al., 2012). In addition, creativity in different types of lessons: In their studies, Rossing et al. (2012) found that the statement with which students identified more than all was "Use of the tablet helped me connect to ideas in new ways." Thus, in classes on English as a foreign language it is possible to repeatedly listen to the study material and to use words, pictures, and sounds to better understand the material. Students in physics classes can watch graphs that depict heights, forces, and speeds. Interviews conducted by Manny-Iken, Berger-Tikochinski, Bashan, and Pesin (2014) show that use of the tablet in different types of lessons has many benefits. In English, it is possible to use an online dictionary in real time to search for explanations and translations of a poem learned in class. In math, it is possible to demonstrate and physically observe quantitative elements such as functions, etc. Another aspect is enjoyment and interest: The tablet provides experiential learning and transforms traditional learning from a book into more interesting and varied learning (Manny-Iken et al., 2014).

\section{Gender and Age Differences}

With regard to gender differences, preferences for STEM and non-STEM subjects it may be associated with gender. A research that examined gifted third graders found that although female adolescents showed an affinity with math and sciences (STEM subjects) they preferred the more verbal (non-STEM) subjects (Olszewski-Kubilius \& Turner, 2002). Moreover, in developed countries, adult women still show less inclination towards STEM subjects than do men; the rate of male students studying scientific-quantitative-engineering disciplines is higher and men are more inclined to choose scientific-quantitative occupations (del Pero \& Bytchkova, 2013). These different gender inclinations towards STEM and non-STEM subjects may generate differences in their perception of cognitive and affective dimensions of tablet use. This resembles Biglan's (1973) previous research, where students of engineering and humanities attributed different weight to the cognitive and affective dimensions.

Differences in tablet use are also evident at different ages. Among younger children, usually at ages 2-8, use of technological products is particularly important for drawing, writing, coloring, thinking games, etc. (Couse \& Chen, 2010). Among elementary school students, use of any type of technology for this purpose raises children's motivation to learn even more than manual writing (Haugland, 1999). When young students experience drawing on a computer or tablet, they learn not only about the art itself but also about how to create it on the device. For example, in addition to drawing an outline or coloring in the lines, the child also learns what happens when he moves the mouse in a certain direction or presses a certain key (Couse \& Chen, 2010). It is possible to see that, among younger children; learning by means of technological tools is more experiential-emotional, characterized by learning from pictures, colors, and shapes. In contrast, Barton and Collura (2003) found in their research that tablet use has benefits for high school aged students due to its ability to organize the considerable amount of writing required of them. The device makes it possible to organize lengthy notes, where manual writing can be illegible and messy. Namely, here it is possible to see that use of the tablet is more learning oriented, as required on the high school level. In this case, the tablet 
Nitza DAVIDOVITCH, Roman YAVICH. The impact of mobile tablet use on students' perception of learning processes

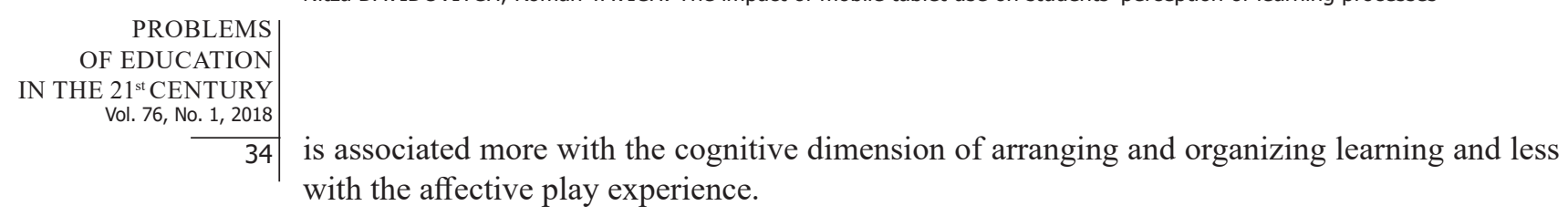

Disadvantages of Tablet Use

Tablets also have technological weaknesses that cannot be disregarded. For instance, the temptation to access domains or sites unrelated to the subject studied in class or to play games (Manny-Iken et al., 2014). In addition, there is the problem of excess information that is not always meaningful and relevant for learning and can inundate and confuse the students. In this context, Rossing et al. (2012) suggest that the teacher must provide the students with direction and assistance to prevent them from losing control. According to Shamir-Inbal and Blau (2013), many teachers who experienced work with tablets reported technological difficulties, such as incompatibility between the known computerized systems and tablet apps. Moreover, from a technological viewpoint digital books are sometimes erased and it is necessary to wait a long time for them to download (Manny-Iken et al., 2014). Fishman and Keller (2011), in their research at Stanford University, found that an attempt to teach with tablets was unsuccessful. Many students could not handle the tool and its operation and thus abandoned its use after several weeks in favor of laptops or more traditional tools. Furthermore, the tablet may not be the ideal form of learning for all students. Students with different learning styles may need different methods of learning. Another disadvantage of tablet use refers to the change in the significance of the teacher's role. Use of tablets might diminish the teacher's role as educator and as an empowering, emotionally supportive educational role model who maintains personal contact with students (Avni \& Rotem, 2013). Accordingly, the research hypotheses are:

1. Students attribute different weight to the cognitive dimension of tablet use in STEM and non-STEM subjects.

2. Students attribute different weight to the affective dimension of tablet use in STEM and non-STEM subjects.

3. Students' age is correlated with their perception of the cognitive and affective dimensions of tablet use. Thus, the older the student the greater the weight attributed to the cognitive dimension of tablet use, and the younger the student the greater the weight attributed to the affective dimension of tablet use.

4. Students differ in their perception of the cognitive and affective dimensions of tablet use by gender. Thus, females attribute more weight to the affective dimension than do male adolescents, and males attribute more weight to the cognitive dimension than do female adolescents.

\section{Methodology of Research}

\section{General Background}

This research, conducted in January to June 2017, explored the impact of tablet use for STEM and non-STEM subjects in Israeli schools on students' perception of the cognitive and affective dimensions of learning processes. Mean, standard deviation, range, and reliability were calculated for all research variables.

The subjects for which the tablet was used the most were history (84\%), English (79.5\%), and biology (76.2\%). Moreover, the findings show that the reliability range of all research variables was high, with Cronbach's alpha of 0.93-0.94. In this research, four hypotheses were explored concerning the cognitive and affective dimensions of tablet use. 
The research included 122 respondents $(\mathrm{N}=122)$, all of them students at the Boyar school in Jerusalem. Of these, 77 were females and 45 male adolescents. Fifty-two students were ninth graders and 70 tenth graders, and the mean age was 15.44 with a standard deviation of 0.62 . The school at which the respondents were sampled uses tablets for almost all research subjects. The minimal age was 14 and the maximal age 16.5. The mean number of siblings was 2.95, with a standard deviation of 1.39. Students' most common first language was Hebrew (112 respondents).

Tools

\section{Demographic questionnaire}

The questionnaire includes several questions on the respondent's personal details, such as age, sex, grade, country of birth, first language, number of siblings, and place of residence.

\section{Questionnaire on pedagogic use of tablets at school for STEM and non-STEM subjects}

The questionnaire includes eight questions. It was administered twice: once with regard to the cognitive dimension and again with regard to the affective dimension. The purpose of the questionnaire was to examine good teaching based on Hativa's (2015) model and it included statements that refer to the cognitive and affective dimensions of the impact of teaching with a tablet. The questionnaire consisted of statements such as "The teacher uses demonstrations (for example by showing films and animation) with the tablet in STEM lessons" and "The students do not have to take notes in class because the research material is saved on the tablet."

The current research found a reliability of $\alpha=.93$ for items pertaining to STEM subjects and $\alpha=.94$ for items pertaining to non-STEM subjects.

\section{Questionnaire on tablet use for STEM and non-STEM subjects}

The questionnaire includes 24 items. It was administered twice: once with regard to the cognitive dimension and again with regard to the affective dimension. The questionnaire included questions about various aspects of tablet use, such as: use of apps, organizing learning, contact with the teacher via the tablet, contact with other students via the tablet, various usages of the tablet for learning purposes, and more. The questionnaire consisted of statements such as "The teacher teaches how to find reliable material in non-STEM subjects online" and "Students create knowledge in class (for instance, via various applications)". The respondents were requested to respond to the questionnaire's items on a scale ranging from 1 (strongly disagree) to 4 (strongly agree). The questionnaire was based on questions that appeared in the research conducted by Dr. Edith Manny-Iken and Tali Berger-Tikochinski (2015). The current research found a reliability of $\alpha=.93$ for items pertaining to STEM subjects and $\alpha=.94$ for items pertaining to non-STEM subjects.

\section{General satisfaction}

Students were requested to rank their general satisfaction with learning via the tablet in non-STEM subjects and separately in STEM subjects and to choose between a low, medium, or high level. 


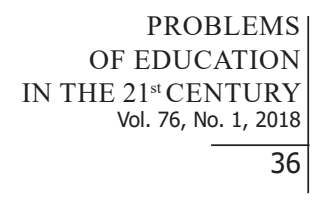

PROBLEMS

$21^{\text {st }}$ CENTURY

36

\section{Procedure}

During 2017, the researchers approached several schools throughout Israel, reported on the internet as schools where students learn with tablets, at random. The researchers contacted the school management by telephone in order to provide details and a general explanation of the research purpose and its process and to receive the school's agreement for students to participate in the research.

The researchers met with a contact person on behalf of the school in order to provide more details of the research and to confirm that the school agrees to administer the questionnaires. At this meeting, the school was also presented with the Ministry of Education's approval of the research. After this process, the researchers came to the school in person. They entered all ninth and tenth grade classes, with about 40 students in each class. The students received an explanation from the researchers and were told that the research deals with tablet use for various subjects in Israeli schools. The questionnaires were administered online via the tablet. Each student received a link to access the questionnaires, which they were requested to complete. Additionally, the students were required to confirm their participation on an informed consent form which explained that the questionnaires are anonymous and that the answers would be used only for purposes of the current research. They were also told that there are several questionnaires and that it will take about 15 minutes to complete them all.

\section{Data Analysis}

The school at which the respondents were sampled uses tablets for almost all research subjects. The minimal age was 14 and the maximal age 16.5. The mean number of siblings was 2.95 , with a standard deviation of 1.39 . Students' most common first language was Hebrew (112 respondents).

\section{Results of Research}

\section{First Hypothesis}

In order to check for differences between STEM and non-STEM subjects in the weight students attribute to the cognitive dimension of tablet use, a t-test for dependent samples was held. This test found no significant differences between STEM and non-STEM subjects in the weight students attribute to the cognitive dimension of tablet use $(\mathrm{t}(120)=.244, \mathrm{p}>.05)$. The first hypothesis was not confirmed.

\section{Second Hypothesis}

In order to check for differences between STEM and non-STEM subjects in the weight students attribute to the affective dimension of tablet use, a t-test for dependent samples was held. This test found no significant differences between STEM and non-STEM subjects in the weight students attribute to the affective dimension of tablet use $(\mathrm{t}(120)=-.84, \mathrm{p}>.05)$. The second hypothesis was not confirmed.

\section{Third Hypothesis}

In this hypothesis, the research checked for a correlation between students' age and the weight attributed to cognitive and affective dimensions of tablet use. Thus, the older the student the more weight is attributed to the cognitive dimension of tablet use, and the younger the 
student the more weight attributed to the affective dimension of tablet use. In order to explore this hypothesis, Pearson correlations were calculated between the variables of age, cognitive dimension of tablet use, and affective dimension of tablet use. According to the findings, no significant correlation was found neither between the variable of age and the cognitive dimension of tablet use $(\mathrm{p}>.05)$ nor between the variable of age and the affective dimension of tablet use ( $p>05)$. Thus, the third hypothesis was not confirmed.

\section{Fourth Hypothesis}

In this hypothesis, t-tests were used to check for gender differences between students' perception of the cognitive and affective dimensions of tablet use, on the assumption that females would attribute more weight to the affective dimension than male adolescents and males, in contrast, would attribute more weight to the cognitive dimension than females. At-test for independent samples found a significant difference between male and female adolescents with regard to the weight attributed to the affective dimension, $\mathrm{t}(82.3)=2.74, \mathrm{p}<.01$. Thus, males attributed more weight to the affective dimension $(\mathrm{M}=2.47, \mathrm{SD}=.61)$ than females $(\mathrm{M}=2.16$, $\mathrm{SD}=.54$ ). The hypothesis concerning the affective dimension was confirmed but not in the expected direction. Then, in a t-test for independent samples, a significant difference was found between males and females with regard to the weight attributed to the cognitive dimension, $\mathrm{t}(88)=2.92, \mathrm{p}<.01$, such that males attributed more weight to the cognitive dimension $(\mathrm{M}=2.50$, $\mathrm{SD}=.61)$ than females $(\mathrm{M}=2.17, \mathrm{SD}=.58)$. The hypothesis with regard to the cognitive dimension was confirmed.

Furthermore, only among the male adolescents, a t-test for dependent samples found a significant difference solely in the STEM subjects between the weight attributed to the cognitive dimension and to the affective dimension, $\mathrm{t}(44)=-2.06, \mathrm{p}<.05$, such that in STEM subjects males attributed more weight to the cognitive dimension $(\mathrm{M}=2.53, \mathrm{SD}=.61)$ than to the affective dimension $(\mathrm{M}=2.46, \mathrm{SD}=.70)$.

In summary, the current research found no significant differences between STEM and non-STEM subjects in the weight attributed to cognitive and affective dimensions of tablet use. Moreover, no correlation was found between students' age and the weight attributed to these cognitive and affective dimensions. Nonetheless, the current research found significant gender differences in the perception of cognitive and affective dimensions of tablet use. Males attributed more weight than females to the cognitive dimension of tablet use, as hypothesized. Males also attributed more weight than female adolescents to the affective dimension of tablet use, in contrast to the hypothesis.

\section{Discussion}

The current research examined the impact of tablet use for various subjects in Israeli schools on students' perception of learning processes in the cognitive and affective dimensions. The main hypotheses were that a difference would be found between STEM and non-STEM subjects in the cognitive and affective dimensions of tablet use.

The first hypothesis, whereby differences exist between STEM and non-STEM subjects in the weight students attribute to the cognitive dimension (lesson organization, lesson clarity, enhancing concentration and attention, intellectual challenge) of tablet use, was not confirmed. Namely, students attributed identical weight to the cognitive dimension of tablet use in STEM and non-STEM subjects and no significant differences were found between the utilization of more cognitive functions, such as: graphs, calculation apps, and various analyses in the different subjects. Moreover, the second hypothesis whereby differences exist between STEM and nonSTEM subjects in the weight students attribute to the affective dimension (interaction between 
IN THE $21^{\text {st }}$ CENTURY Vol. 76, No. 1,2018

38

students, student-teacher interaction, motivation, enjoyment, interest, and creativity in class) of tablet use was not confirmed. Namely, students attributed identical weight to the affective dimension of tablet use in STEM and non-STEM subjects and no significant differences were found between these subjects in the utilization of affective dimensions of tablet use, such as information sharing between students and teacher, information search, presentations, and drawing.

The researchers suggest that tablets are used uniformly and similarly by students in the current sample in all subjects, with no congruence between certain academic usages of the tablet and the type of subject. Students do not make use of the tablet's unique features and do not sufficiently utilize its special properties for each subject. For example, no regular use is made in math classes of apps that present graphs and facilitate calculations. In the researchers' opinion, in all subjects students mostly use the tablet merely as a digital alternative for notebooks and textbooks. This explanation is compatible with the research conducted by Manny-Iken, BergerTikochinski, Bashan, and Wolf (2015) who examined three tenth grades in which personal tablets had been introduced for all students. They found that the tablet was commonly used mainly as an alternative to textbooks. Students in their research testified that they use the apps on the tablet they received as a learning environment for marking the digital book and adding notes and bookmarks. Further, Sofer, Kahn and Livne (2014) also reported that the main prevalent use of tablets at the school they studied was as textbooks.

Evidence that tablets are not used for a variety of study options beyond serving as a digital book in the school studied is provided by some of the students' responses. About $64 \%$ of the students answered that they do not use the tablet's photography app, about $62 \%$ answered that they do not use message sending to the teacher via the tablet and that they either do not agree or slightly agree with the statement that they create knowledge with the tablet in class. About $82 \%$ answered that the teacher does not teach how to summarize material from the web and about $90 \%$ answered that the teacher does not teach how to find reliable material related to the subject online via the tablet. In contrast, the students gave answers that reinforce the explanation whereby the tablet is used more as a digital book. About $63 \%$ of the students answered that they use the tablet to adapt study needs such as enlarging/reducing print, listening to written text, etc., and also that the teacher gives homework on the tablet.

Another explanation of the findings in the two first hypotheses may be that teachers do not always receive proper training in teaching with tablets and thus are not capable of managing the lesson in a way that potentially integrates tablets. This is also true of utilizing the range of qualities offered by tablets for more comfortable, interesting, and challenging learning. Personal conversations with teachers in the school studied showed that their professional training in tablet use is not always sufficient. Blackwell, Lauricella, Wartella, Robb and Schomburg (2013) present the idea of "barriers teachers face when integrating technology ". They contend that teachers' initial barrier is indeed, as mentioned above, the concrete barrier to integrating technology in class and its proper use. Namely, a lack of teacher training on how to teach with tablets, technological support, and knowledge of the programs to which they provide access. Another barrier is more emotional, stemming of course partially from the first barrier, and it includes personal access to technology, self-confidence, and anxiety with regard to use of technology, inclination towards technology, and willingness to experience it. When one manages to overcome the first barrier it is possible to deal with these subsequent difficulties as well, which together affect the integration of tablets in the classroom as an enriching and regenerating means of learning.

The third hypothesis claims that there is a correlation between the student's age and his or her perception of the cognitive and affective dimensions of tablet use. Thus, the older the student the greater the weight attributed to the cognitive dimension compared to the affective dimension and the younger the student the greater the weight attributed to the affective dimension. This 
hypothesis was not confirmed. The findings show no correlation between students' age and the weight they attribute to the different dimensions. A possible explanation of this finding is that in this research the classrooms sampled did not encompass a significant age range. All students were about 15-16 years old. If it had been possible to sample students with a significant age range the correlation between age and various dimensions of tablet use may have been different. For example, sampling seventh grade students from the beginning of junior high school who are busy getting to know new students, new teachers, and may be more interested in affective aspects, versus twelfth graders at the end of high school who may make use of tablets to study for matriculation exams - a more cognitive use.

The fourth hypothesis was that gender differences would be found in students' perception of the cognitive and affective dimensions of tablet use. Thus, while females would attribute more weight to the affective dimension than male adolescents, males would attribute more weight to the cognitive dimension than females. The fourth hypothesis was partially confirmed. Males attributed more weight than females to both the cognitive and affective dimensions. The finding whereby males attributed more weight to the cognitive dimension than females may be explained by the male inclination towards STEM subjects. Various studies show that men prefer and choose to study STEM subjects more than women. As stated, the proportion of male students studying scientific-quantitative-engineering fields is higher and men are more inclined to choose scientific-quantitative occupations (del Pero \& Bytschkova, 2013). According to the Israel Central Bureau of Statistics, as of 2017 men constitute a significant majority of students studying the physical sciences (63\%), math, statistics, and computer sciences $(70 \%)$, as well as engineering and architecture (72\%), in Israeli institutions of higher education.

Furthermore, the current research found that in STEM subjects only males attributed more weight to the cognitive dimension than to the affective dimension. This finding resembles that reported by Biglan (1973), where students of STEM subjects attributed more weight to cognitive dimensions of learning such as lesson clarity and lesson organization than did students of non-STEM subjects. In the context of the current research, it is possible that males attributed more weight to the cognitive dimension of tablet use than females since males naturally constitute a majority of students in STEM subjects and show an inclination for them, and these subjects include a stronger emphasis on cognitive dimensions of learning.

The added finding whereby males attributed more weight to the affective dimension than did females proved significant but in the opposite direction to the hypothesis. The researchers hypothesized that gender differences would be found in the perception of cognitive and affective dimensions of tablet use, such that females would perceive the affective dimensions as more important than would males. This may be related to a sampling error or specific limitations of the current research, such as the small sample and the large discrepancy between the number of male and female adolescents. However, it is also possible that this is no error and that this result was affected by other factors. The researchers would like to suggest a direction that may constitute one explanation among many for this finding. Gender differences in the weight attributed to the affective dimension of tablet use may stem from natural differences in inherent character traits between the genders. For example, Levin, Rubinek and Amiad (1981) found a difference between males and females in the competitiveness dimension reflecting the degree to which class students compete against each other and the teacher's encouragement of this competitiveness. Males also perceived the degree of competitiveness in the classroom as higher than did females. Namely, in the affective dimension males are more competitive than females and they try to lead in situations of group dynamics and versus the teacher. Thus, they may perceive affective use of tablets as a means of maintaining their social status within the class and versus the teacher, an advantage which serves them well in interactions among the students and with the teacher. 
CALMS

OF EDUCATION

IN THE $21^{\text {st }}$ CENTURY Vol. 76, No. 1,2018

40

\section{Research Limitations and Recommendations for Further Research}

The current research has several limitations. First of all, it included only one school that does not represent all Israeli students. Hence, the sample is homogeneous with regard to place of residence, socioeconomic status, style of teaching and learning, level of teachers, etc. Furthermore, the school studied has specific operational problems with tablets, such as the inability to use an external camera, which affect the quality of using tablets for learning purposes. This problem does not exist in all Israeli schools and it affected some of the students' perceptions regarding tablet use. Second, the sample was comprised of only 122 respondents. A larger number of students may have been capable of affecting the significance of the results. Third, the research did not include an equal representation of male and female adolescents (77 female versus 45 males). A different gender ratio may produce different results. Fourth, the age difference between the grades was not sufficiently large (ninth versus tenth grades - ages 15-16). To begin with, the intention was to include a larger age range, such as seventh versus twelfth grades, in order to examine the third hypothesis which explored the correlation between various ages and the weight attributed to the tablet's dimensions, but this did not prove possible.

In future studies it is suggested that use be made of a larger sample that includes students from several schools, as equal a ratio as possible of males and females, and a more meaningful difference between respondents' ages. Another suggestion is to further investigate the contrary finding to the current hypothesis, whereby males attributed greater weight to the affective dimension than did females, as well as the gender differences in perceiving the various dimensions of tablet use. At the same time, the character traits suggested here as inherent in the various sexes, such as competitiveness, should be examined as well as their implications for tablet use in the classroom.

It appears that in the school studied, which represents the situation in the Israeli school system to a certain degree, tablet use is still in its initial stages. There is need to provide teachers and students with thorough instruction in acquiring the necessary skills for proper and high standard use of this device in order to enjoy its various benefits for learning. The researchers suggest that teachers be instructed about the tablet in more thorough and extensive courses and that they be given periodical further education as new developments are constantly emerging. Perhaps in this way the tablet will serve not only as a digital alternative for textbooks and notebooks rather as a well-developed learning tool. Moreover, designated lessons can be held for students, in which they will engage in acquiring advanced learning methods of various subjects using tablets.

\section{Conclusions}

With the passing years, the entire world is advancing in a more technological and digital direction and leaving behind traditional forms of learning. People increasingly consume news through smartphones instead of print newspapers, read digital books, universities are moving towards advanced platforms such as presentations, models, etc. It seems that Society is undergoing deep processes of transition "from print to digital". This is also true of the various school systems around the world. It is increasingly important to be proficient in utilizing digital resources for higher standard and better learning. If the tablet's uniqueness and benefits for learning are not utilized, its disadvantages may overcome its advantages and society may come to miss the qualities of traditional learning. The researchers expected to find differences between STEM and non-STEM subjects in the weight attributed to the cognitive and affective dimensions of tablet use. The research hypotheses were only partially confirmed and indicate the significance of high standard and meaningful assimilation of tablet use for learning and pedagogy in the current era. 


\section{References}

Avni, I., \& Rotem, A. (2011). A renaissance of ethics and trust in digital learning: The classroom is present in the student's ipad. Online Ethics Project website. http://ianethics.com/2781-2 [Hebrew].

Barton, C., \& Collura, K. (2003). Catalyst for change. T.H.E. Journal, 31 (4), 39-41. Retrieved January 25, 2018 from https://www.learntechlib.org/p/77052/.

Biglan, A. (1973). The characteristics of subject matter in different academic areas. Journal of Applied Psychology, 57 (3), 195-203. http://dx.doi.org/10.1037/h0034701.

Blackwell, C. K., Lauricella, A. R., Wartella, E., Robb, M., \& Schomburg, R. (2013). Adoption and use of technology in early education: The interplay of extrinsic barriers and teacher attitudes. Computers \& Education, 69, 310-319.

Borse, J., \& Sloan, K. (2005). A case study of DyKnow Vision: Conversations and observations that demonstrate its educational potential (case study). Bloomington, Indiana: Rockman et al.

Central Bureau of Statistics (2017). Data compilation on the occasion of the International Women's Day. Central Bureau of Statistics website. http://www.cbs.gov.il/reader/newhodaot/hodaa_template. html?hodaa=201711064 [Hebrew].

Leslie J. Couse, Dora W. Chen. (2010). A tablet computer for young children? Exploring its viability for early childhood education. Journal of Research on Technology in Education, 43 (1), 75-98. https://pdfs.semanticscholar.org/daad/284d8fdddf3075556377144e50a1822abdc1.pdf.

Del Pero, A. S., \& Bytchkova, A. (2013). A bird's eye view of gender differences in education in OECD countries. OECD Social, Employment and Migration Working Papers, No. 149, OECD Publishing. http://dx.doi.org/10.1787/5k40k706tmtb-en.

Donald, J. G. (2000, April). Indicators of success: From concepts to classrooms. Paper presented at the Annual Meeting of the American Educational Research Association. New Orleans, LA, April 2428, 2000. https://eric.ed.gov/?id=ED441858.

Fischman, J., \& Keller, J. (2011). College tech goes mobile. Chronicle of Higher Education, 58 (1), 50.

Harris, J., Mishra, P., \& Koehler, M. (2009). Teachers' technological pedagogical content knowledge and learning activity types: Curriculum-based technology integration reframed. Journal of Research on Technology in Education, 41 (4), 393-416.

Hativa, N. (2014). What does the research say about good teaching and the excellent teacher? Hora'ah Ba'akademya, 4, 43-59. [Hebrew].

Haugland, S. W. (1999). What role should technology play in young children's learning? Young Children, 54 (9), 26-30.

Levin, T., Rubinek, B., \& Amiad, R. (1981). How do students perceive the academic-social atmosphere in their classroom? Iyunim Bechinuch, 29, 87-96. [Hebrew].

Mang, C. F., \& Wardley, L. J. (2012). Effective adoption of tablets in post-secondary education: Recommendations based on a trial of iPads in university classes. Journal of Information Technology Education Innovations in Practice, 11 (1), 301-317.

Manny-Ikan, E., Berger-Tikochinski, T., Bashan, Z., \& Pesin, G. (2014). The tablet project of Forward Science at a school in northern Israel 2014 - Summary of evaluation findings in three tenth grades. Henrietta Szold Institute website. https://www.szold.org.i1/he/?s=\%D7\%98\%D7\%90\%D 7\%91\%D7\%9C\%D7\%98\&s ubmit=\%D7\%97\%D7\%A4\%D7\%A9 [Hebrew].

Manny-Ikan, E., Berger-Tikochinski, T., Bashan, Z., \& Wolf, A. (2015). Use of tablets in class Implications for teaching and learning. In Y. Eshet-Alkalai, I. Blau, A. Caspi, N. Geri, Y. Kalman, $\&$ V. Silber-Varod (Eds.), Proceedings of the 10th chais conference for the study of innovation and learning technologies 2015: Learning in the technological era. Raanana: The Open University. [Hebrew].

Melhuish, K., \& Falloon, G. (2010). Looking to the future: M-learning with the ipad. Computers in New Zealand Schools: Learning, Leading, Technology, 22 (3), 1-16.

Olszewski-Kubilius, P., \& Turner, D. (2002). Gender differences among elementary school-aged gifted students in achievement, perceptions of ability, and subject preference. Journal for the Education of the Gifted, 25 (3), 259.

Rossing, J. P., Miller, W. M., Cecil, A. K., \& Stamper, S. E. (2012). ILearning: the future of higher education? Student perceptions on learning with mobile tablets. Journal of the Scholarship of Teaching and Learning, 12 (2), 14. 
Nitza DAVIDOVITCH, Roman YAVICH. The impact of mobile tablet use on students' perception of learning processes

OF EDU

IN THE $21^{\text {st }}$ CENTURY

Vol. 76, No. 1, 2018

Rotem, A., \& Avni, I. (2013). Learning with personal tablets. Online ethics project website. http:// ianethics.com/wp-content/uploads/2013/06/personal-tablet-class-AI.pdf [Hebrew].

Shamir-Inbal, T., \& Blau, I. (2013). Tablets in elementary school: Is the technology ready for pedagogical innovation? In Y. Eshet-Alkalai, A. Caspi, S. Eden, N. Geri, \& Y. Yair (Eds.), Learning in the technological era. Ra'anana: The Open University. [Hebrew].

Sharples, M., Taylor, J., \& Vavoula, G. (2007). A theory of learning for the mobile age. In R. Andrews and

C. Haythornthwaite (Eds.). The Sage handbook of e-learning research (pp. 221-247). London: Sage.

Sofer, T., Kahn, T., \& Livne, E. Evaluation of the use of tablets for learning purposes: Results of a survey of high school students. Virtuval TAU website - Online academic teaching and learning, School of Education, Tel Aviv University. [Hebrew].

Received: January 15, 2018

Accepted: February 20, 2018

Nitza Davidovitch

PhD, Head of Academic Development, Ariel University, P.O. Box 3, Ariel, Israel.

E-mail: d.nitza@ariel.ac.il

Roman Yavich

PhD, Ariel University, P.O. Box 3, Ariel, Israel.

E-mail: romany@ariel.ac.il 